\title{
Gastric Emptying of Low- and High-Caloric Liquid Meals Measured Using Ultrasonography in Healthy Volunteers
}

\section{(ㄷ) (i) (오 $€$}

\author{
Authors \\ Tarek Mazzawi¹, 2, Emily Bartsch², Sara Benammi², Rosa Maria Carrasco Ferro², Ekaterina Nikitina², Nancy Nimer², \\ Lara Jiménez Ortega², Charles Perrotte ${ }^{2}$, Joäo Vitor Pithon², Safira Rosalina², Alexis Sharp², Reza Stevano², \\ Jan Gunnar Hatlebakk ${ }^{1,2}$, Trygve Hausken ${ }^{1,2}$
}

\section{Affiliations \\ 1 Department of Medicine, Haukeland University Hospital, Bergen, Norway \\ 2 Clinical Medicine, University of Bergen, Bergen, Norway}

Key words

antral area, caloric meal, functional dyspepsia,

gastric emptying, ultrasonography

$\begin{array}{ll}\text { received } & 08.05 .2018 \\ \text { revised } & 23.09 .2018 \\ \text { accepted } & 27.10 .2018\end{array}$

Bibliography

DOI https://doi.org/10.1055/a-0783-2170

Ultrasound Int Open 2019; 5: E27-E33

(c) Georg Thieme Verlag KG Stuttgart · New York

ISSN 2199-7152

Correspondence

Dr. Tarek Mazzawi

Haukeland University Hospital

Medicine, Gastroenterology

Jonas Lies vei 65

5021 Bergen

Norway

Tel.: +47/559/75 000, tarek.mazzawi@gmail.com

\section{ABSTRACT}

Purpose Delayed gastric emptying is present in patients with functional dyspepsia (FD), diabetes mellitus, and neurological diseases. Diet may affect gastric emptying symptoms in patients with FD. We sought to determine the extent to which gastric emptying and symptoms of dyspepsia are influenced by caloric content in healthy subjects using ultrasonography.

Materials and Methods 32 healthy volunteers were given 2 meals with different caloric content in random order. Gastric emptying was determined using ultrasonography to measure antral area when fasting, and postprandially at intervals of 0 , 10,20 , and $30 \mathrm{~min}$. Dyspeptic symptoms including discomfort, nausea, and fullness were graded.

Results The antral area following a high-caloric meal compared to a low-caloric meal was significantly increased at 0,10 , 20 , and $30 \mathrm{~min}(P=0.0203,<0.0001<0.0001,<0.0001$, respectively), as was the median fullness $(P<0.0048,0.0001$, $0.0009,0.0001$, respectively) measured at the same time points. There was a weak correlation $(r 2=0.1, \mathrm{P}<0.0001)$ between the antral area and subjective fullness. No differences between gastric emptying in males and females were found. Conclusion The caloric content of a meal influences gastric emptying. Using ultrasonography to measure the antral area helps us to assess gastric emptying and therefore to assess patients with functional dyspepsia.

\section{Introduction}

Functional dyspepsia (FD) is a gastroduodenal disorder that presents with symptoms despite having no organic, systemic, or metabolic cause [1]. It is characterized by epigastric pain or discomfort, postprandial fullness, early satiety, and nausea [2]. Upper gastrointestinal symptoms such as nausea, belching, or abdominal bloating can also occur [3]. At least $20 \%$ of the general population experiences symptoms of dyspepsia, and a majority of those people are believed to have FD $[1,4]$. Patients with FD experience reduced quality of life and there are significant costs to the healthcare system [5].
The underlying mechanism behind FD includes poor receptive accommodation of the proximal stomach, visceral hypersensitivity, and delayed gastric emptying [6]. The symptoms in patients with delayed gastric emptying worsen following meals high in fat, mass, and/or high in calories [7]. Therefore, patients with FD eat fewer meals and consume less total energy and fat than their healthy counterparts [8]. Gastric emptying is delayed in approximately $30 \%$ of patients with FD [9] as well as $30-50 \%$ of patients with longstanding diabetes mellitus [10]. Therefore, the measurement of 
gastric emptying may be useful in understanding the severity of dyspeptic symptoms.

The gold standard for measuring gastric emptying is scintigraphy [11]. Other reliable methods include the octanoic acid breath test [12], magnetic resonance imaging (MRI) [13], gastric aspiration techniques, epigastric impedance measurements, applied potential tomography [14], and paracetamol absorption test and other tracer methods [15]. Ultrasonography has been used for over 30 years to measure gastric emptying by observing the changes in cross-sectional antral area [16]. It has been suggested that the reliable location and identification of the gastric antrum makes it a particularly useful method of measurement [17]. Ultrasound is noninvasive, does not change the physiology of the gastrointestinal tract, and is widely available in outpatient settings [18].

The aims of this study were to evaluate gastric emptying in healthy volunteers following low- vs. high-caloric liquid meals as measured by the antral area $\left(\mathrm{cm}^{2}\right)$ using ultrasonography, to explore whether the presentation of any dyspeptic symptoms is associated with delayed gastric emptying and to investigate if ultrasonography can also be used as a reliable method in clinical practice to assess gastric emptying in healthy volunteers (based on what is previously known concerning the physiological gastric emptying of low- vs. high-caloric liquid meals).

\section{Materials and Methods}

\section{Participants}

From 2015 to 2017,32 healthy volunteers aged 19 to 35 , with a median age of 22, were recruited to participate in the study at the Division of Gastroenterology, Haukeland University hospital, Bergen, Norway. A senior gastroenterologist (T.H.) performed an ultrasound scan of the abdomen and pelvic regions of each participant to rule out the presence of any abnormalities. The researchers completing the ultrasound were medical students that did not have extensive previous experience with ultrasound that were supervised by a gastroenterologist (T.M and T.H) to limit the inter-examiner variability, answer any questions and to confirm the location of the antrum.

\section{Meals}

Two beverages were used in this study. The first was a low-caloric meal using $400 \mathrm{ml}$ commercial meat soup (Toro clear meat soup, Rieber \& Søn A/S, Bergen, Norway) that was prepared with boiling water $\left(100^{\circ} \mathrm{C}\right)$ then cooled to room temperature. The soup was cooled to prevent changes in gastric emptying rate that may be associated with very hot or very cool temperatures [19]. The second beverage was a high-caloric meal using two $200 \mathrm{ml}$ nutritional juice supplements (Nutridrink Juice style, Nutricia AS, Oslo, Norway). The juice was consumed at room temperature. The nutritional characteristics of both meals can be found in $>$ Table 1 .

\section{Study design}

Each participant fasted for a minimum of $4 \mathrm{~h}$ prior to the study. The participants were randomized [20] to begin with either the low- or high-caloric liquid meal. Each participant drank the beverage within $2 \mathrm{~min}$. Immediately after finishing the meal, the participants were asked about their dyspeptic symptoms, and the antral area was re-
- Table 1 Nutritional characteristics of low- and high-caloric meals.

\begin{tabular}{|c|c|c|}
\hline & Low-caloric soup $(400 \mathrm{ml})$ & High-caloric drink (400 ml) \\
\hline Protein & $1.5 \mathrm{~g}$ & $15.6 \mathrm{~g}$ \\
\hline Fat & $1.0 \mathrm{~g}$ & $0.0 \mathrm{~g}$ \\
\hline Carbohydrate & $3.5 \mathrm{~g}$ & g \\
\hline Salt & $4.8 \mathrm{~g}$ & $0.08 \mathrm{~g}$ \\
\hline Calories & 30 kcal & $600 \mathrm{kcal}$ \\
\hline
\end{tabular}

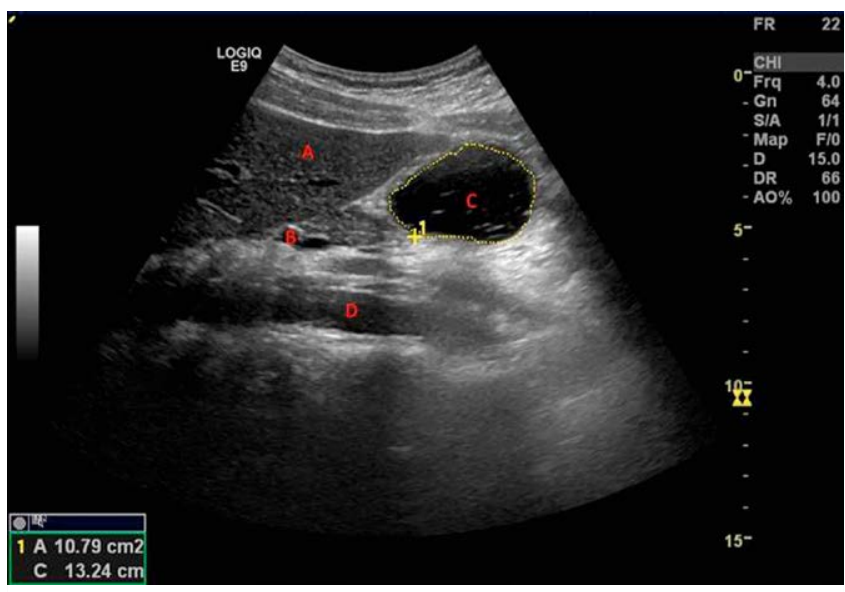

Fig. 1 Representative ultrasonography image (this image was taken 10 min after a low-caloric liquid meal). Landmarks: A: liver, B: superior mesenteric vein, C: gastric antrum and D: aorta.

corded. Ultrasonography (Logic E9 ultrasound scanner General Electric Healthcare, Milwaukee, WI, 4-MHz curvilinear probe) was used to measure the cross-sectional area of the antrum of the stomach. The cross-sectional area of the antrum, abdominal aorta and superior mesenteric vein served as landmarks, - Fig. 1. The outer profile of the antrum was measured using the built-in caliper and calculation program of the ultrasound apparatus. The measurements were performed between antral contractions while the participants suspended their breathing in expiration. A minimal amount of force was applied during each reading to prevent compression of the antrum. In addition, it was ensured that all participants were kept in the same-seated position throughout the experiment, as it has been shown that body position may influence postprandial perceptions, gastric emptying, and intragastric meal distribution [21]. To ensure the accuracy of the results, the measurements were taken twice and then averaged.

The antral area was measured at 5 different time points: in the fasting state, immediately following liquid meal intake ( 0 min), and at 10,20 , and $30 \mathrm{~min}$ postprandially. At each time point, the participants were asked to record the severity of each dyspeptic symptom (discomfort, fullness, and nausea) on a Likert scale from zero (absence of symptoms) to 10 (maximum severity). 2-6 days later the participants drank the opposite meal and the same protocol was repeated. 
The study was approved by the Regional Ethics Committee of western Norway (ref.nr.: 2016/1206).

\section{Statistics}

The statistical software used for this project was GraphPad Prism 7.00. Normal distribution of the data was assessed using the D’Agostino \& Pearson normality test complemented by a graphical method (histograms). The comparison of the antral area following low- and high-caloric meals was done at each time point using a Tukey's multiple comparison test (area under the curve). The same statistical test was performed to compare the antral area of females and males at each time point. Each participant served as their own control when comparing antral areas at different time points.

Moreover, the median fullness, nausea and discomfort following low- and high-caloric meals were compared at each time point using a non-parametric test, Wilcoxon signed-rank test. Median and interquartile ranges were calculated for the symptoms of dyspepsia at each time point for both the low- and high-caloric meal. Using a linear regression model, we also calculated the correlation $\left(r^{2}\right)$ with corresponding P-value between the antral area and subjective fullness.

\section{Results}

The weight and height of each participant were measured and the body mass index (mean \pm SD) was $22.56 \pm 2.51 \mathrm{~kg} / \mathrm{m}^{2}$. The antral area was significantly larger after the high-caloric meal compared to the low-caloric meal, at 0, 10, 20, and $30 \mathrm{~min}$ ( $>$ Fig. 2, $>$ Table 2). The antral area after the high-caloric liquid meal stayed relatively constant in each postprandial measurement compared to the antral area after the low-caloric liquid meal, which decreased at a faster rate. The difference between $30 \mathrm{~min}$ and $0 \mathrm{~min}$ in the case of the high-caloric meal was $1.487 \mathrm{~cm}^{2}$, whereas the same difference in the low-caloric meal was $6.497 \mathrm{~cm}^{2}$. Differences between the means of the antral areas after a low- and a high-caloric liquid meal were calculated

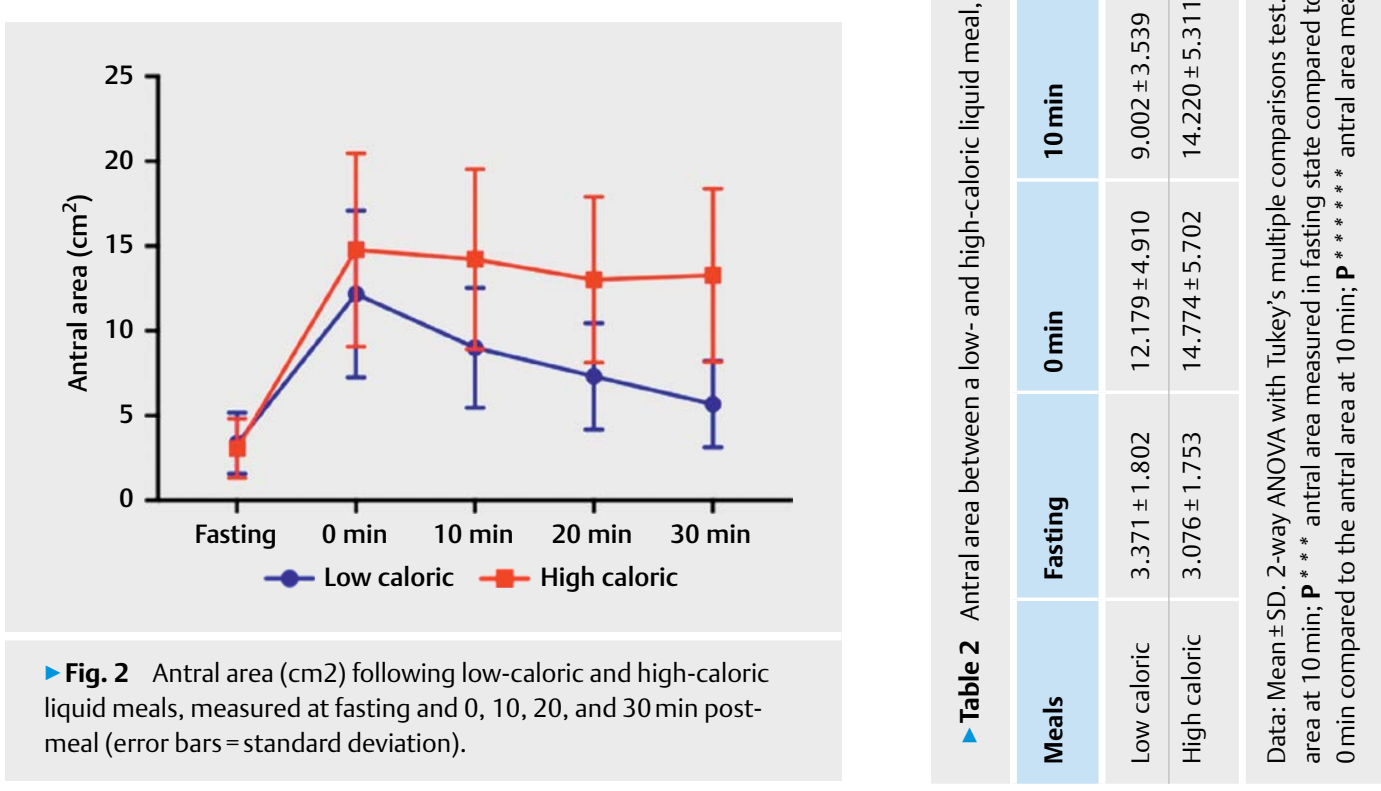


with a $95 \%$ confidence interval $(\mathrm{Cl})$. The difference in antral area increases between a high- and a low-caloric meal over a 30-min postprandial period. Moreover, the $\mathrm{Cl}$ at each time point does not come in contact with the $x$-axis, therefore, indicating the significance of the findings, $>$ Fig. 3 . There was no significant difference in antral area during fasting $(\mathrm{P}=0.9705)$.

The median results at all times for low- and high-caloric liquid meals in both nausea and discomfort were 0 , and the results showed no significant difference in nausea between low- and high-caloric liquid meals. There was only one significant difference with respect to discomfort at the 10 -min interval. The median fullness scores are shown in $>$ Table 3 . There was no significant difference with respect to fullness during the fasting state. While participants ingesting the high-caloric meal reported a relatively constant sensation of fullness throughout the intervals, participants consuming the low-caloric meal reported a steady decrease in fullness at each interval, $\mathbf{r i g} \mathbf{4}$.

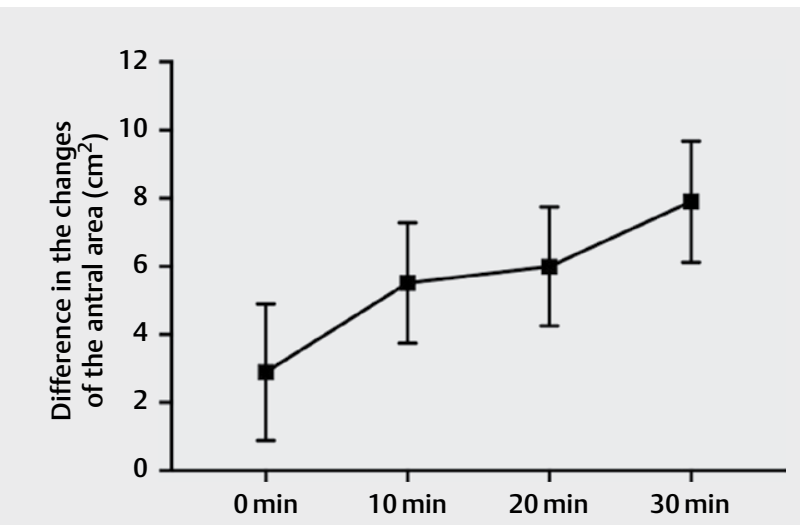

-Fig. 3 The differences in the changes of the antral area $(\mathrm{cm} 2)$ following a low-caloric and a high-caloric liquid meal, measured at 0 , 10,20 , and 30 min post-meal (error bars $=95 \%$ confidence interval).
When values of all antral area measurements from both low- and high-caloric liquid meals were gathered and compared to the reports of subjective fullness, the data shows that there was a weak correlation $\left(r^{2}=0.1, p<0.0001\right)$ between antral area and subjective fullness for both the low- and high-caloric liquid meals, > Fig. 5. However, there was no correlation between antral area and the other dyspeptic symptoms (nausea and discomfort).

There were no significant differences in the antral area between males and females after consumption of a low-caloric meal ( $\vee$ Table 4, >Fig. 6) or a high-caloric meal (> Table 5, > Fig. 7).

\section{Discussion}

The current study on the usage of ultrasonography for determining the antral area of the stomach of healthy participants before and after low- and high-caloric meals shows that gastric emptying

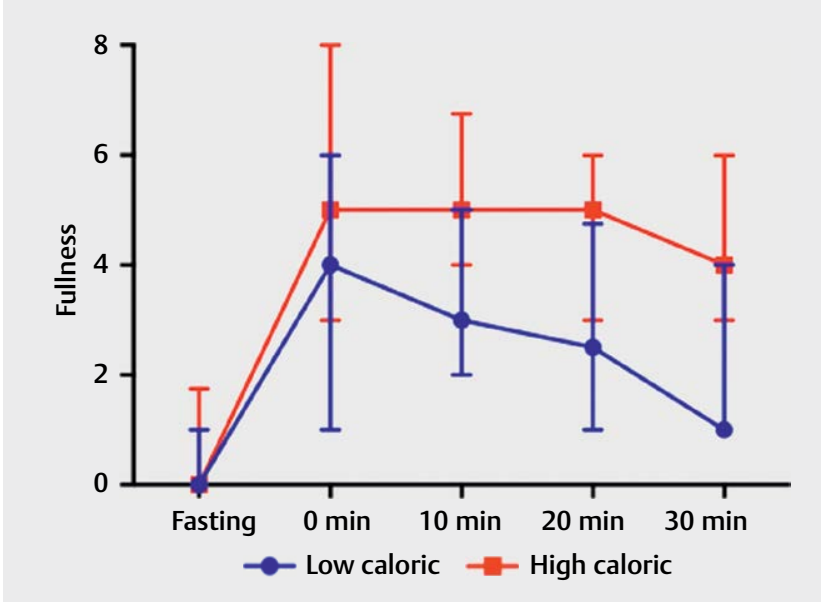

Fig. 4 Median of fullness, on a scale of 0-10, between low-caloric and high-caloric liquid meals, taken at fasting and $0,10,20$, and 30 min after a meal (error bar = interquartile range).

- Table 3 Dyspeptic symptoms (median \pm IQR) following a) a low-caloric and b) a high-caloric liquid meal.

\begin{tabular}{|c|c|c|c|c|c|}
\hline \multirow[t]{2}{*}{ Symptom } & \multicolumn{5}{|c|}{ Median (IQR) following a low-caloric meal } \\
\hline & Fasting & $0 \mathrm{~min}$. & $10 \mathrm{~min}$. & $20 \mathrm{~min}$. & $30 \mathrm{~min}$. \\
\hline Discomfort & $0.0(0.0,0.0)$ & $0.0(0.0,0.0)$ & $0.0(0.0,0.0)$ & $0.0(0.0,0.0)$ & $0.0(0.0,0.0)$ \\
\hline Nausea & $0.0(0.0,0.0)$ & $0.0(0.0,0.0)$ & $0.0(0.0,0.0)$ & $0.0(0.0,0.0)$ & $0.0(0.0,0.0)$ \\
\hline Fullness & $0.0(0.0,1.0)$ & $4.0(1.0,6.0)$ & $3.0(2.0,5.0)$ & $2.5(1.0,4.8)$ & $1.00(1.0,4.0)$ \\
\hline \multirow[t]{2}{*}{ Symptom } & \multicolumn{5}{|c|}{ Median (IQR) following a high-caloric meal } \\
\hline & Fasting & $0 \mathrm{~min}$. & $10 \mathrm{~min}$. & $20 \mathrm{~min}$. & $30 \mathrm{~min}$. \\
\hline Discomfort & $0.0(0.0,0.0)$ & $0.0(0.0,1.0)$ & $0.0(0.0,1.0)$ & $0.0(0.0,0.0)$ & $0.0(0.0,0.0)$ \\
\hline Nausea & $0.0(0.0,0.0)$ & $0.0(0.0,0.0)$ & $0.0(0.0,0.0)$ & $0.0(0.0,0.0)$ & $0.0(0.0,0.0)$ \\
\hline Fullness & $0.0(0.0,1.8)$ & $5.0(3.0,8.0)$ & $5.00(4.0,6.8)$ & $5.0(3.0,6.0)$ & $4.00(3.0,6.0)$ \\
\hline
\end{tabular}




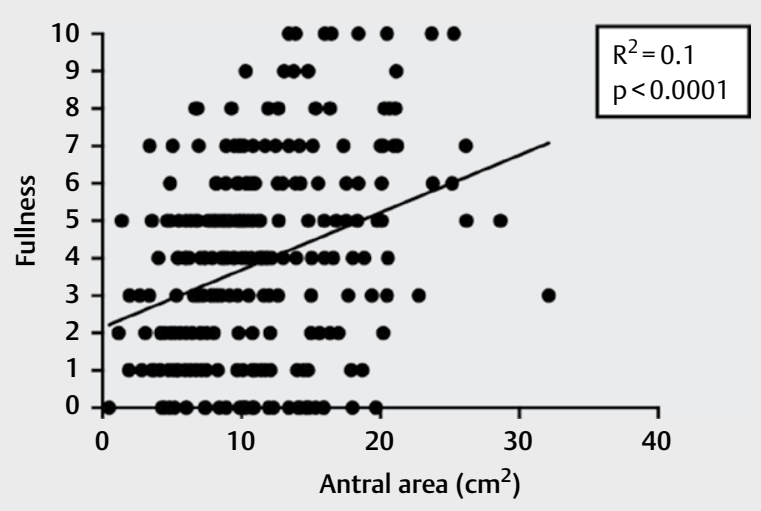

> Fig. 5 The relationship between subjective fullness, rated on a scale from 0 to 10 , and antral area $(\mathrm{cm} 2)$.

- Table 4 Antral area between females and males in fasting state and postprandially using a low-caloric liquid meal, at intervals of $0,10,20$, and $30 \mathrm{~min}$.

\begin{tabular}{|l|r|r|l|}
\hline Time (min) & \multicolumn{1}{|l|}{ Females } & \multicolumn{1}{l|}{ Males } & P-value \\
\hline Fasting & $3.16 \pm 1.56$ & $3.85 \pm 2.76$ & 0.46 \\
\hline 0 & $11.36 \pm 6.16$ & $10.35 \pm 2.68$ & 0.69 \\
\hline 10 & $9.16 \pm 1.05$ & $8.4 \pm 4.04$ & 0.69 \\
\hline 20 & $7.77 \pm 3.34$ & $6.67 \pm 3.59$ & 0.49 \\
\hline 30 & $5.48 \pm 2.36$ & $5.47 \pm 3.24$ & 0.99 \\
\hline
\end{tabular}

Data: Mean \pm SD. Multiple $t$ test.

is more rapid in the case of a low-caloric meal compared to a high-caloric meal. Furthermore, the antral area recedes to nearly the fasting size after $30 \mathrm{~min}$ following the consumption of a low-caloric meal.

The antral area was significantly larger following the consumption of a high-caloric meal compared to that after a low-caloric meal, suggesting slower gastric emptying in the case of a high-caloric meal, which is consistent with previous publications [22-25]. In fact, at 30 min the antral area following consumption of a low-caloric meal receded to nearly the fasting size. A similar relationship can also be observed with fullness. Fullness is a normal sensation that can be expected after a meal, and thus does not necessarily indicate the presence of dyspepsia [26]. Therefore, it was not expected that healthy participants would experience nausea or discomfort after either meal. Fullness was significantly higher after high-caloric meals than low-caloric meals. However, it is important to note that there may be other factors contributing to feelings of fullness between the 2 meals. For example, research shows that salivation, swallowing, and tasting, all assess oral food intake and inhibit the hypothalamus-feeding center [27].

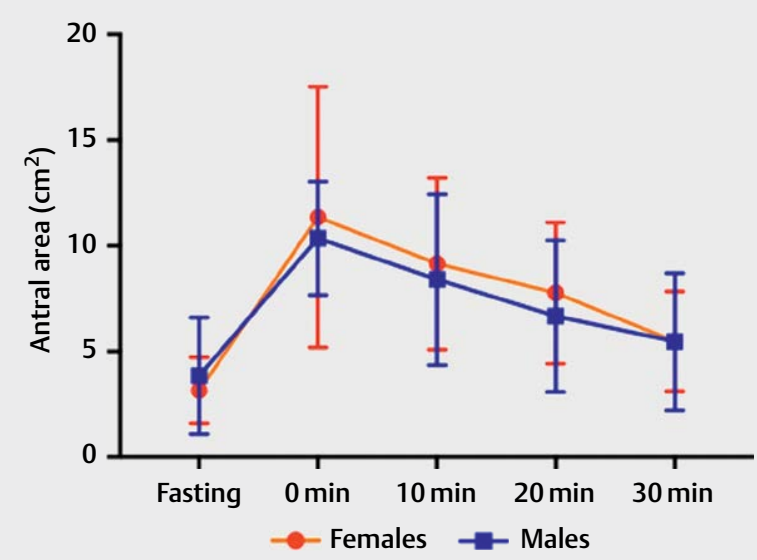

- Fig. 6 Antral area in females and males before and after eating a low-caloric meal measured at fasting and $0,10,20$ and 30 min.

- Table 5 Antral area between females and males in fasting state and postprandially using a high-caloric liquid meal, at intervals of 0,10 , 20 , and $30 \mathrm{~min}$.

\begin{tabular}{|l|l|l|l|}
\hline Time (min) & Females & Males & P-value \\
\hline Fasting & $2.54 \pm 1.48$ & $4.02 \pm 2.79$ & 0.11 \\
\hline 0 & $15.62 \pm 6.5$ & $14.93 \pm 5.97$ & 0.81 \\
\hline 10 & $14.97 \pm 6.5$ & $14.85 \pm 5.76$ & 0.97 \\
\hline 20 & $13.63 \pm 4.7$ & $13.82 \pm 6.38$ & 0.94 \\
\hline 30 & $14.65 \pm 5.9$ & $11.93 \pm 5.35$ & 0.31 \\
\hline
\end{tabular}

Data: Mean \pm SD. Multiple $t$ test.

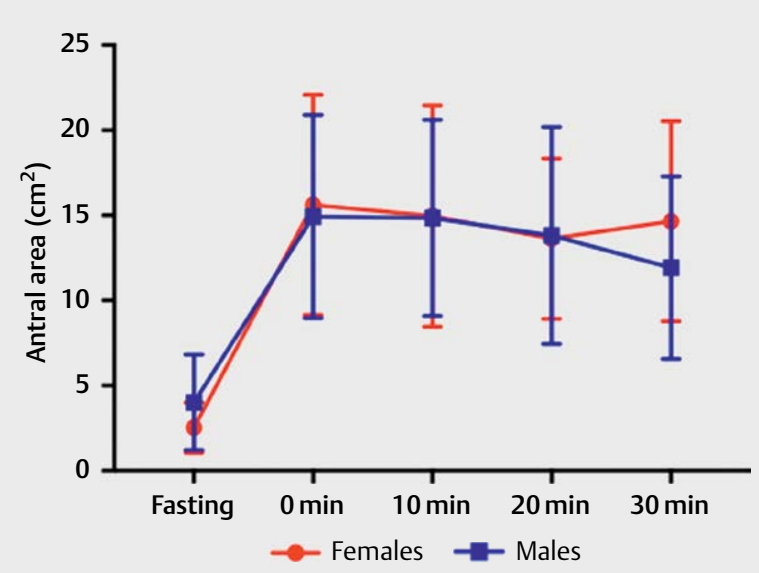

- Fig. 7 Antral area in females and males before and after eating a high-caloric liquid meal measured at fasting and 0, 10, 20 and $30 \mathrm{~min}$. 
Furthermore, a weak correlation between antral area and subjective fullness was found when observing results for both low- and high-caloric meals. Although a small connection between these 2 factors exists, this relationship does not determine a fixed trend in which the antral area can be accurately predicted based on subjective fullness alone. In addition, each individual perceives fullness uniquely, which adds variability to the ratings of fullness.

Previous research suggests that there may be a difference in gastric emptying in females between the follicular and luteal phases of the menstrual cycle. For example, one study found gastric emptying to be slower during the luteal phase compared to the follicular phase [28]. On the other hand, other studies denied any relationship between gastric emptying and the menstrual cycle [29]. However, with the small sample size, we were not able to find any statistical differences between males and females.

Using ultrasound easily aids in determining the antral area in patients with FD [9]. Since antral area $<5 \mathrm{~cm}^{2}$ in the fasting state is considered normal [30], values more than that may indicate FD. Functional ultrasonography is an easy, effective and noninvasive modality that can be used in clinical practice to evaluate gastric emptying in both healthy patients and those with conditions such as diabetes mellitus and gastrointestinal disorders, such as FD [31]. Compared to scintigraphy, the gold standard for gastric emptying measurements, ultrasound is less expensive, and there is no exposure to ionizing radiation [32]. Furthermore, ultrasound allows real-time imaging with conveniently mobile instruments and it can be combined with many other procedures to broaden its applications [33]. In addition, the "gold standard" title is being challenged by 3D ultrasound. This technique has proven itself more accurate and less variable than standard 2D ultrasound, especially when visualizing the entire stomach and measuring volumes [34]. Gentilcore and colleagues found no significant difference for 3D ultrasound with scintigraphy for the measurement of gastric emptying rate [35].

\section{Limitations}

The participants were randomized to have either a high- or a low-caloric meal first. In hindsight, it would have been valuable for the researcher completing the ultrasound to also be blinded to the caloric value of the meal.

We realized that gastric function and emptying might change according to the time of the day. However, with the short nature of this study, we were not able to limit the ultrasound examinations to a certain time of the day.

It occasionally took up to 3 min to obtain 2 readings of the antrum with the abdominal aorta and superior mesenteric vein visualized. However, this challenge occurred in trials of both high and low calories, therefore providing consistency.

\section{Conclusion}

Ultrasound is a noninvasive, non-radiating and inexpensive method for the assessment of gastric emptying by measuring the gastric antral area. This technique is easy to master, even by medical students, and it allows us to find the same trend, which is supported by other studies performed with a gold standard test, without any exposure to radiation. These findings may help guide potential dietary recommendations for patients experiencing symptoms of dyspepsia, as well as aid in future research regarding the subject.

\section{Acknowledgements}

Dr. Odd Helge Gilja for his support throughout this program, Dr. Kim Nylund for his assistance with ultrasound. For the participants in the study, who made this project possible and IFMSA for enabling this exchange.

\section{Conflict of Interest}

No conflict of interest has been declared by the authors.

References

[1] Tack J, Talley NJ, Camilleri M et al. Functional gastroduodenal disorders. Gastroenterology 2006; 130: 1466-1479

[2] Lacy BE. Functional dyspepsia and gastroparesis: one disease or two? The American Journal of Gastroenterology 2012; 107: 1615-1620

[3] Tack J, Talley NJ. Functional dyspepsia--symptoms, definitions and validity of the Rome III criteria. Nature reviews Gastroenterology \& Hepatology 2013; 10: 134-141

[4] Camilleri M, Dubois D, Coulie B et al. Prevalence and socioeconomic impact of upper gastrointestinal disorders in the United States: Results of the US Upper Gastrointestinal Study. Clinical Gastroenterology and Hepatology : The Official Clinical Practice Journal of the American Gastroenterological Association 2005; 3: 543-552

[5] Asano T, Aida S, Suemasu S et al. Aldioxa improves delayed gastric emptying and impaired gastric compliance, pathophysiologic mechanisms of functional dyspepsia. Scientific Reports 2015; 5: 17519

[6] Timmons S, Liston R, Moriarty KJ. Functional dyspepsia: Motor abnormalities, sensory dysfunction, and therapeutic options. The American Journal of Gastroenterology 2004; 99: 739-749

[7] Clegg M, Shafat A. Energy and macronutrient composition of breakfast affect gastric emptying of lunch and subsequent food intake, satiety and satiation. Appetite 2010; 54: 517-523

[8] Horowitz M, Wishart JM, Jones KL, Hebbard GS. Gastric emptying in diabetes: An overview. Diabetic Medicine : A Journal of the British Diabetic Association 1996; 13: S16-S22

[9] Steinsvik EK, Hausken T, Gilja OH. The ultrasound meal accommodation test in 509 patients with functional gastrointestinal disorders. Scandinavian Journal of Gastroenterology 2016; 51: 788-794

[10] Stevens JE, Gilja OH, Gentilcore D et al. Measurement of gastric emptying of a high-nutrient liquid by 3D ultrasonography in diabetic gastroparesis. Neurogastroenterology and motility : The Official Journal of the European Gastrointestinal Motility Society 2011; 23: 220-225 e113-224

[11] Abell TL, Camilleri M, Donohoe K et al. Consensus recommendations for gastric emptying scintigraphy: a joint report of the American Neurogastroenterology and Motility Society and the Society of Nuclear Medicine. Journal of Nuclear Medicine Technology 2008; 36: 44-54

[12] Ghoos YF, Maes BD, Geypens B] et al. Measurement of gastric emptying rate of solids by means of a carbon-labeled octanoic acid breath test. Gastroenterology 1993; 104: 1640-1647

[13] Schwizer W, Maecke H, Fried M. Measurement of gastric emptying by magnetic resonance imaging in humans. Gastroenterology 1992; 103 : 369-376 
[14] Gilja OH, Hausken T, degaard S, Berstad A. Gastric emptying measured by ultrasonography. World Journal of Gastroenterology : WJG 1999; 5: 93-94

[15] Willems M, Quartero AO, Numans ME. How useful is paracetamol absorption as a marker of gastric emptying? A systematic literature study. Digestive Diseases and Sciences 2001; 46: 2256-2262

[16] Bolondi L, Bortolotti M, Santi V et al. Measurement of gastric emptying time by real-time ultrasonography. Gastroenterology 1985; 89: 752-759

[17] Perlas A, Chan VW, Lupu CM, Mitsakakis N, Hanbidge A. Ultrasound assessment of gastric content and volume. Anesthesiology 2009; 111 : 82-89

[18] Elbl B, Birkenfeld B, Walecka A et al. Upper gastrointestinal tract scintigraphy and ultrasonography in diagnosis of gastroesophageal reflux in children. Polish Journal of Radiology 2011; 76: 63-67

[19] Mishima Y, Amano Y, Takahashi Y et al. Gastric emptying of liquid and solid meals at various temperatures: effect of meal temperature for gastric emptying. J Gastroenterol 2009; 44: 412-418

[20] 2016. SEL. Create a blocked randomisation list, 2016. Online] Available from https://www.sealedenvelope.com/simple-randomiser/v1/lists [Accessed 26 June 2016]

[21] Valeur J, Berstad A, Hausken T. The effect of body position on postprandial perceptions, gastric emptying, and intragastric meal distribution: an ultrasonographic study in reclining healthy subjects. Scandinavian Journal of Gastroenterology 2015; 50: 170-173

[22] Quigley EM. Gastric and small intestinal motility in health and disease. Gastroenterology Clinics of North America 1996; 25: 113-145

[23] Velchik MG, Reynolds JC, Alavi A. The effect of meal energy content on gastric emptying. Journal of nuclear medicine : Official publication, Society of Nuclear Medicine 1989; 30: 1106-1110

[24] Calbet JA, MacLean DA. Role of caloric content on gastric emptying in humans. The Journal of Physiology 1997; 498 (Pt 2): 553-559

[25] Peracchi M, Gebbia C, Ogliari C et al. Influence of caloric intake on gastric emptying of solids assessed by 13C-octanoic acid breath test. Scandinavian Journal of Gastroenterology 2000; 35: 814-818
[26] Caldarella MP, Azpiroz F, Malagelada JR. Antro-fundic dysfunctions in functional dyspepsia. Gastroenterology 2003; 124: 1220-1229

[27] Ahima RS, Antwi DA. Brain regulation of appetite and satiety. Endocrinology and Metabolism Clinics of North America 2008; 37: 811-823

[28] Gill RC, Murphy PD, Hooper HR, Bowes KL, Kingma Y]. Effect of the menstrual cycle on gastric emptying. Digestion 1987; 36: 168-174

[29] Horowitz M, Maddern G], Chatterton BE et al. The normal menstrual cycle has no effect on gastric emptying. British journal of obstetrics and gynaecology 1985; 92: 743-746

[30] Hausken T, Berstad A. Wide gastric antrum in patients with non-ulcer dyspepsia. Effect of cisapride. Scandinavian Journal of Gastroenterology 1992; 27: 427-432

[31] Muresan C, Surdea Blaga T, Muresan L, Dumitrascu DL. Abdominal Ultrasound for the Evaluation of Gastric Emptying Revisited. Journal of Gastrointestinal and Liver Diseases : JGLD 2015; 24: 329-338

[32] Darwiche G, Almer LO, Bjorgell O, Cederholm C, Nilsson P. Measurement of gastric emptying by standardized real-time ultrasonography in healthy subjects and diabetic patients. Journal of ultrasound in medicine : Official Journal of the American Institute of Ultrasound in Medicine 1999; 18: 673-682

[33] Odegaard S, Nesje LB, Hausken T, Gilja OH. Ultrasonography in gastroenterology. Scandinavian Journal of Gastroenterology 2015; 50: 698-707

[34] Gilja OH, Lunding J, Hausken T, Gregersen H. Gastric accommodation assessed by ultrasonography. World Journal of Gastroenterology : WJG 2006; 12: 2825-2829

[35] Gentilcore D, Hausken T, Horowitz M, Jones KL. Measurements of gastric emptying of low- and high-nutrient liquids using 3D ultrasonography and scintigraphy in healthy subjects. Neurogastroenterology and motility : The Official Journal of the European Gastrointestinal Motility Society 2006; 18: 1062-1068 